\title{
Reflex peristalsis in the guinea pig isolated ileum is endogenously controlled by kappa opioid receptors
}

Naunyn-Schmiedeberg's Arch Pharmacol (1990) 341:450-454

\section{W. Kromer}

Two unfortunate typesetting errors occurred:

Page 450, right column, second paragraph, line 16 should read: "nor-binaltorphimine" instead of "binaltorphimine".

According to the above references, the $\mathrm{K}_{e}$ values of nor-binaltorphimine at $\kappa$ receptors, naloxone and CTOP-NH$H_{2}$ at $\mu$ receptors and ICI 174,864 at $\delta$ receptors differ (i.e., being ca. $0.41,1.5$, 1.4 and $22 \mathrm{nmol} / 1$, respectively).

Page 453, left column, second paragraph, line 7 should read 13 instead of 1 :

According to their apparent dissociation constants at the $\mu$ receptor (i.e., 13 and $1.5 \mathrm{nmol} / \mathrm{l}$ for nor-binaltorphimine and naloxone, respectively; same ref.), naloxone should had been more potent than nor-binaltorphimine in case the $\mu$ receptor instead of the $\kappa$ receptor was predominantly functional. 